\title{
New insights into the low-temperature oxidation of
}

\section{2-methylhexane}

\author{
Zhandong Wang ${ }^{a^{*}}$, Samah Y. Mohamed ${ }^{\mathrm{a}}$, Lidong Zhang ${ }^{\mathrm{b}}$, Kai Moshammer ${ }^{\mathrm{c}}$, Denisia M. \\ Popolan-Vaida ${ }^{\mathrm{d}}$, Vijai Shankar Bhavani Shankar ${ }^{\mathrm{a}}$, Arnas Lucassen ${ }^{\mathrm{e}}$, Lena Ruwe ${ }^{\mathrm{f}}$, Nils Hansen ${ }^{\mathrm{c}}$, \\ Philippe Dagaut g, S. Mani Sarathy ${ }^{\text {** }}$
}

${ }^{a}$ Clean Combustion Research Center, King Abdullah University of Science and Technology, Thuwal 23955-6900, Saudi Arabia

${ }^{b}$ National Synchrotron Radiation Laboratory, University of Science and Technology of China, Hefei, Anhui 230029, P. R. China

${ }^{c}$ Combustion Research Facility, Sandia National Laboratories, Livermore, CA 94551, USA

${ }^{d}$ Departments of Chemistry and Physics, University of California, Berkeley, CA 94720, and Chemical Sciences Division, Lawrence Berkeley National Laboratory, Berkeley, CA 94720, USA

${ }^{e}$ Physikalisch-Technische Bundesanstalt, Bundesallee 100, D-38116 Braunschweig, Germany

${ }^{f}$ Department of Chemistry, Bielefeld University, D-33615 Bielefeld, Germany

g Centre National de la Recherche Scientifique (CNRS), INSIS, 1C, Avenue de la recherche scientifique, 45071, Orléans

Cedex 2, France

Abstract: In this work, we studied the low-temperature oxidation of a stoichiometric 2-methylhexane $/ \mathrm{O}_{2} / \mathrm{Ar}$ mixture in a jet-stirred reactor coupled with synchrotron vacuum ultraviolet photoionization molecular-beam mass spectrometry. The initial gas mixture was composed of $2 \%$ 2-methyhexane, $22 \% \mathrm{O}_{2}$ and $76 \% \mathrm{Ar}$ and the pressure of the reactor was kept at 780 Torr. Low-temperature oxidation intermediates with two to five oxygen atoms were observed. The detection of $\mathrm{C}_{7} \mathrm{H}_{14} \mathrm{O}_{5}$ and $\mathrm{C}_{7} \mathrm{H}_{12} \mathrm{O}_{4}$ species suggests that a third $\mathrm{O}_{2}$ addition process occurs in 2-methylhexane low-temperature oxidation. A detailed kinetic model was developed that describes the third $\mathrm{O}_{2}$ addition and subsequent reactions leading to $\mathrm{C}_{7} \mathrm{H}_{14} \mathrm{O}_{5}$ (keto-dihydroperoxide and dihydroperoxy cyclic ether) and $\mathrm{C}_{7} \mathrm{H}_{12} \mathrm{O}_{4}$ (diketo-hydroperoxide and keto-hydroperoxy cyclic ether) species. The kinetics of the third $\mathrm{O}_{2}$ addition reactions are discussed and model calculations were performed that reveal that third $\mathrm{O}_{2}$ addition reactions promote 2-methylhexane auto-ignition at low temperatures.

\footnotetext{
*Corresponding author: E-mail: zhandong.wang@kaust.edu.sa (Z. Wang), mani.sarathy@kaust.edu.sa (S. M. Sarathy)
} 
Keywords: auto-oxidation; highly oxidized multifunctional molecules; peroxides; alternative isomerization; synchrotron VUV photoionization mass spectrometry

\section{Introduction}

Detailed kinetic models for hydrocarbon fuels are important for improving combustion efficiency and reducing pollutant emission. Among real fuels (e.g., gasoline, diesel, and jet fuels), straight-chain (normal) and branched (iso) paraffins are common species, and thus selected as important components in surrogate fuels [1,2]. This study is concerned with the auto-oxidation of 2-methylhexane, which is an important component for surrogate fuels [1-3]. It is a continuation of the earlier work of Wang et al. [4] in which the oxidation of 2,5-dimethylhexane was studied. This work is of particular interest because detailed studies on heptane isomers have revealed that low-temperature auto-oxidation and auto-ignition are particularly affected by the number and location of methyl branches $[5,6]$.

Kinetic models for oxidation of large hydrocarbons are typically developed using reaction classes and rate rules [7]. To simulate low-temperature auto-oxidation chemistry, the classical reaction scheme involving the $\mathrm{O}_{2}$ addition on fuel radicals $(\mathrm{R})$ and hydroperoxy alkyl radicals $(\mathrm{QOOH})$ (note: $\mathrm{R}=\mathrm{C}_{\mathrm{n}} \mathrm{H}_{2 \mathrm{n}+1}, \mathrm{Q}=\mathrm{C}_{\mathrm{n}} \mathrm{H}_{2 \mathrm{n}}$ ) is commonly adopted [8]. Recently, Ranzi et al. [9] proposed three new reaction classes in the low-temperature auto-oxidation of n-alkanes, i.e., H-atom abstraction from keto-hydroperoxides to form dicarbonyl compounds, the Korcek decomposition mechanism of keto-hydroperoxides, and recombination/disproportionation reactions of peroxy radicals. Bugler et al. [10] and Zhang et al. [11] considered the alternative isomerization of hydroperoxy alkylperoxy radicals $(\mathrm{OOQOOH})$ to dihydroperoxy alkyl radicals $\left(\mathrm{P}(\mathrm{OOH})_{2}, \mathrm{P}=\mathrm{C}_{\mathrm{n}} \mathrm{H}_{2 \mathrm{n}-1}\right)$ in the kinetic modeling of pentanes and n-hexane. In their reaction schemes, the $\mathrm{P}(\mathrm{OOH})_{2}$ radicals decompose into hydroperoxy cyclic ethers and/or olefinic hydroperoxides. Wang et al. [4] detected highly oxidized multifunctional (HOM) molecules with five and four oxygen atoms during the auto-oxidation of 2,5-dimethylhexane in a jet-stirred reactor (JSR). The authors proposed a third $\mathrm{O}_{2}$

addition reaction scheme to $\mathrm{P}(\mathrm{OOH})_{2}$ radicals, which predicts additional radical chain branching 
intermediates. Wang and Sarathy [12] also studied the effect of the third $\mathrm{O}_{2}$ addition reactions on the ignition of n-pentane and n-hexane. They found that the extended mechanism has only a slight effect on n-pentane ignition, but promotes n-hexane ignition at low temperatures.

Recently, Mohamed et al. [13] updated the thermodynamic data and the kinetic reaction mechanism for 2-methylhexane (2MHX) using updated group values and rate rules derived from quantum calculations and experiments. The model was compared against high- and low-temperature 2MHX ignition delay times measured in shock tube and rapid compression machine. The authors also investigated the alternative isomerization pathways for OOQOOH radicals. This work studies the low-temperature oxidation chemistry of $2 \mathrm{MHX}$ in a JSR. Besides the well-known species governing auto-ignition, species with four and five oxygen atoms were detected, suggesting the existence of a third $\mathrm{O}_{2}$ addition process also in $2 \mathrm{MHX}$ auto-oxidation. To simulate the experimental observation of the third $\mathrm{O}_{2}$ addition process, the $2 \mathrm{MHX}$ chemical kinetic model from Mohamed et al. [13] was extended to include the third $\mathrm{O}_{2}$ addition to $\mathrm{P}(\mathrm{OOH})_{2}$ radicals and subsequent reactions of $\mathrm{OOP}(\mathrm{OOH})_{2}$ radicals. This work describes the kinetics of 2-methylhexane low-temperature auto-oxidation with a focus on $\mathrm{C}_{7} \mathrm{H}_{14} \mathrm{O}_{3}$ species (e.g., keto-hydroperoxdes (KHP) and hydroperoxy cyclic ethers (HPCE)), $\mathrm{C}_{7} \mathrm{H}_{14} \mathrm{O}_{2}$ species (e.g., olefinic hydroperoxides (OHP)), $\mathrm{C}_{7} \mathrm{H}_{12} \mathrm{O}_{4}$ species (e.g., diketo-hydroperoxides (DKHP) and keto-hydroperoxy cyclic ethers (KHPCE)), and $\mathrm{C}_{7} \mathrm{H}_{14} \mathrm{O}_{5}$ species (e.g., keto-dihydroperoxides (KDHP) and dihydroperoxy cyclic ethers (DHPCE)). Finally, homogenous batch reactor simulations were performed to show that third $\mathrm{O}_{2}$ addition reactions promote the low-temperature auto-ignition of $2 \mathrm{MHX}$ and predict better the ignition properties of 2MHX [13].

\section{Experimental and computational methods}

The experiment was performed at Terminal 3 of the Chemical Dynamics Beamline of the Advanced Light Source at the Lawrence Berkeley National Laboratory. The low-temperature oxidation of a stoichiometric $2 \mathrm{MHX}(2 \%) / \mathrm{O}_{2}(22 \%) / \mathrm{Ar}(76 \%)$ mixture was investigated in a JSR $\left(\mathrm{V}=33.5 \mathrm{~cm}^{3}\right)$ coupled with a high-resolution time-of-flight molecular-beam mass spectrometer that relies on 
tunable synchrotron-generated vacuum ultraviolet (VUV) radiation for photoionization. The reactor was kept at a quasi-atmospheric pressure of 780 Torr and temperatures between 530 and $740 \mathrm{~K}$. Gas flows were adjusted to achieve a residence time of $0.5 \mathrm{~s}$. The temperature was measured by a K-type thermocouple located in the vicinity of the sampling position. The uncertainty in reactor temperature is estimated to be $\pm 20 \mathrm{~K}$ [4]. The JSR product gases are analyzed by a custom-built reflectron time-of-flight system with a sensitivity of $1 \mathrm{ppm}$, a dynamic range of several orders of magnitude, and a mass resolution of $m / \Delta m \sim 2500$. The experimental method is similar to the work of Battin-Leclerc and Qi et al. [14-16]. Details of the experimental setup have been described by Moshammer et al. [17].

Theoretical computational chemistry is needed to interpret the complex mass spectra and to explore chemical structures based on observed ionization thresholds. To this end, adiabatic ionization energies (IE) were calculated from the composite CBS-QB3 method [18] using Gaussian09 [19]. For each species, the structure has been optimized for minimum energy. However, the structure may not represent the global energy minimum. The uncertainty of the calculated IEs is estimated to be \pm 0.05 eV [18], which doesn't include the uncertainty from excluding all conformeric structures. Calculated adiabatic ionization energies of conformeric structures can differ by as much as $0.5 \mathrm{eV}$ [17], which basically precludes structural assignments.

\section{Kinetic model development}

Recently, Mohamed et al. [13] studied the ignition chemistry of $2 \mathrm{MHX}$ with a comprehensive chemical kinetic model. The low-temperature oxidation mechanism includes 20 classes of reactions in the classical reaction scheme [7], the alternative isomerization of $\mathrm{OOQOOH}$ to $\mathrm{P}(\mathrm{OOH})_{2}[20,21]$, the subsequent decomposition of $\mathrm{P}(\mathrm{OOH})_{2}$ (e.g., C-O $\beta$-scission), and their cyclization to HPCE and $\mathrm{OH}[10,11]$. Only formation of $\mathrm{P}(\mathrm{OOH})_{2}$ radicals derived from the $\mathrm{OOQOOH}$ via six-membered transition state (TS) ring were considered. This simplification is reasonable because six-membered TS ring isomerizations are favorable in most cases compared with other TS geometries. The thermochemical data and rate rules were updated with new group values [22] and quantum-chemistry 
calculations [20,21,23-25], respectively.

In this work, the third $\mathrm{O}_{2}$ addition to $\mathrm{P}(\mathrm{OOH})_{2}$, and subsequent pathways of $\mathrm{OOP}(\mathrm{OOH})_{2}$ were added to the 2MHX kinetic model of Mohamed et al. [13] following a similar methodology proposed by Wang et al. [4,12]. The subsequent pathways of $\mathrm{OOP}(\mathrm{OOH})_{2}$ include the following three classes: (i) $\mathrm{H}$-atom migrations of the $\mathrm{C}-\mathrm{H}$ attached to the $-\mathrm{OOH}$ group and $\mathrm{C}-\mathrm{O} \beta$-scission to $\mathrm{KDHP}+\mathrm{OH}$; (ii) intramolecular $\mathrm{H}$-atom migrations of the $\mathrm{C}-\mathrm{H}$ attached to the non $-\mathrm{OOH}$ group to form $\mathrm{T}(\mathrm{OOH})_{3}$, which cyclizes to DHPCE $+\mathrm{OH}$ and/or $\mathrm{C}-\mathrm{O} \beta$-scission to olefinic dihydroperoxides $(\mathrm{ODHP})+\mathrm{HO}_{2}$; and (iii) concerted eliminations of $\mathrm{HO}_{2}$ to form ODHP. Alternative isomerization of $\mathrm{OOP}(\mathrm{OOH})_{2}$ to $\mathrm{T}(\mathrm{OOH})_{3}$ via six-membered $\mathrm{TS}$ rings were considered, while seven-membered $\mathrm{TS}$ ring isomerizations were considered when six-membered TS ring isomerizations are not available. H-atom abstractions from KDHP and DHPCE were included with subsequent decomposition to DKHP and KHPCE, respectively [4,12]. The decompositions of KDHP, DHPCE, ODHP, DKHP, and KHPCE were treated analogously to the decomposition of KHP (i.e., homolytic dissociation of $-\mathrm{OOH})$. Scheme 1 presents the detailed reaction pathways of OOQOOH radicals, wherein alternative isomerizations and subsequent reactions are highlighted. The thermochemistry of new species were estimated using the THERM software [26] with new group values from Burke et al. [22].

Table 1 shows the rate rules utilized in the third $\mathrm{O}_{2}$ addition reaction mechanism, which were derived by analogy to similar reactions of $\mathrm{QOOH}, \mathrm{OOQOOH}, \mathrm{P}(\mathrm{OOH})_{2}$, and $\mathrm{KHP}$ from Mohamed et al. [13] to ensure self-consistency within the kinetic model. The detailed model of $2 \mathrm{MHX}$ is provided in the Supplemental Material (SM). The kinetic model was compared against the experimental JSR data using transient perfectly stirred reactor simulations in the CHEMKIN PRO software [27] with an end time of $20 \mathrm{~s}$. This is an arbitrary number wherein the only important criteria is to run the simulation long enough so that species mole fractions cease to change with time.

\section{Results and discussion}

Figure 1a shows the mass spectrum in the range of $\mathrm{m} / z=126-180$ taken at $10.5 \mathrm{eV}$ and a reactor temperature of $560 \mathrm{~K}$. The molecular formula for a specific $\mathrm{m} / \mathrm{z}$ signal depends on kinetic analyses, 
following the methodology of Wang et al. [4]. According to the classical and extended reaction scheme [4], we identified $m / z$ values at $130.10,146.09,160.07$, and 178.08 as $\mathrm{C}_{7} \mathrm{H}_{14} \mathrm{O}_{2}, \mathrm{C}_{7} \mathrm{H}_{14} \mathrm{O}_{3}$, $\mathrm{C}_{7} \mathrm{H}_{12} \mathrm{O}_{4}$, and $\mathrm{C}_{7} \mathrm{H}_{14} \mathrm{O}_{5}$, respectively. The temperature distributions of the above species were measured, but mole fraction quantification was not feasible due to the lack of absolute photoionization cross sections for species at these $m / z$ values. Thus only the temperature dependent mass spectrometer signals of these species are compared with the simulated profiles. Quantitative measurements of $2 \mathrm{MHX}$ were possible because its calibration factor was calculated based on the flow conditions at $530 \mathrm{~K}$ (assuming that no oxidation reactions occur at this temperature); its measured concentration is captured by the kinetic model indicating a good reproduction of global reactivity (Fig. 1b). In addition, the mass peaks corresponding to $\mathrm{C}_{7} \mathrm{H}_{13} \mathrm{O}_{2}\left(\mathrm{~m} / z\right.$ 129.10) and $\mathrm{C}_{7} \mathrm{H}_{13} \mathrm{O}_{3}$ $(m / z$ 145.09) were also observed, which may originate from the fragmentation of larger molecules such as $\mathrm{C}_{7} \mathrm{H}_{14} \mathrm{O}_{3}$ and $\mathrm{C}_{7} \mathrm{H}_{14} \mathrm{O}_{5}$ at $10.5 \mathrm{eV}$, respectively.

The present study focuses on tentatively assigning probable structures of several key intermediates based on measured photoionization efficiency (PIE) curves, calculated ionization energies, but mainly modeled concentration profiles. Here, we focus on the kinetics of KHP formation and new reaction pathways in our extended auto-oxidation scheme (i.e., the alternative isomerization of $\mathrm{OOQOOH}$ and third $\mathrm{O}_{2}$ addition reaction scheme).

\subsection{KHP formation from OOQOOH}

The $\mathrm{O}_{2}$ addition to $\mathrm{QOOH}$ radicals produces $\mathrm{OOQOOH}$ radicals, whose $\mathrm{H}$-atom migration from the $\mathrm{C}-\mathrm{H}$ alpha to the hydroperoxy $(-\mathrm{OOH})$ forms $\mathrm{HOOQ} \mathrm{OOH}^{\prime}$ radicals. The HOOQ'OOH radicals are $\alpha$-hydroperoxyalkylhydroperoxy radicals and can decompose to KHP and OH radicals (Scheme 1). The former is the main chain branching species, which further decomposes to generate more $\mathrm{OH}$ radicals.

This study observed a peak with $m / z 146.09$, which corresponds to $\mathrm{C}_{7} \mathrm{H}_{14} \mathrm{O}_{3}$ (KHP). As will be discussed later, the $\mathrm{C}_{7} \mathrm{H}_{14} \mathrm{O}_{3}$ profile may also include HPCE. The simulated KHP profiles reproduce the measured temperature-dependent profile of $\mathrm{C}_{7} \mathrm{H}_{14} \mathrm{O}_{3}$ in Fig. 1c. Figure 2 shows the energy scan 
for $m / z$ 146.10, and clear onsets appear at 8.8 and $9.0 \mathrm{eV}$. The calculated IEs of 24 potential KHP isomers were found to range from 8.83 to $9.46 \mathrm{eV}$ when neglecting effects of conformeric structures. (see Table S1 in the SM). The calculated IE's of more than 10 species are near the observed thresholds at 8.8 and $9.0 \mathrm{eV}$, thus making a definitive isomeric assignment impossible.

The modeling calculations predict that the six most abundant isomers are 2-methyl-2-hydroperoxy-hexan-4-one (KHP-1 in Table. S1, mole fraction: 7.9×10-4), 2-methyl-5-hydroperoxy-hexan-3-one (KHP-2, mole fraction: $\left.\quad 7.2 \times 10^{-4}\right)$, 2-methyl-2-hydroperoxy-hexan-5-one (KHP-3, mole fraction: $\left.4.1 \times 10^{-4}\right)$, 2-methyl-3-hydroperoxy-hexanal (KHP-4, mole fraction: $\quad 1.4 \times 10^{-4}$ ), 2-methyl-3-hydroperoxy-hexan-5-one (KHP-5, mole fraction: $4.6 \times 10^{-5}$ ), and 5-methyl-5-hydroperoxy-hexanal (KHP-6, mole fraction: 3.0×10-5). Except for KHP-3 and KHP-6, the hydroperoxy and carbonyl functional groups of the other four KHPs (e.g., KHP-1, KHP-2, $\mathrm{KHP}-4$, and KHP-5) is separated by one carbon atom, indicating that ROO radicals mainly isomerize via six-membered TS rings. The formation of KHP-3 and KHP-6 indicates that the seven-membered and eight-membered TS ring isomerizations are competitive with six-membered TS ring isomerizations, especially when tertiary $\mathrm{C}-\mathrm{H}$ is involved [23].

\subsection{Alternative isomerization of $\mathrm{OOQOOH}$ to $\mathrm{P}(\mathrm{OOH})_{2}$}

Recently, Bugler et al. [10] and Zhang et al. [11] developed detailed kinetic models for pentanes and n-hexane to study their ignition chemistry. The authors proposed the alternative isomerization of OOQOOH to $\mathrm{P}(\mathrm{OOH})_{2}$, which further cyclize to $\mathrm{HPCE}$ and $\mathrm{OH}$ and/or decompose to $\mathrm{OHP}$ and $\mathrm{HO}_{2}$ (Scheme 1). The $\mathrm{P}(\mathrm{OOH})_{2}$ was selected to denote the alternative isomerization products, which is distinct from the $\mathrm{HOOQ}^{\prime} \mathrm{OOH}$ produced from the classical scheme. It should be noted that $\mathrm{P}(\mathrm{OOH})_{2}$ has the same molecular formula as $\mathrm{HOOQ}^{\prime} \mathrm{OOH}$, but the radical positions are different. In this work, we detected signal at $\mathrm{m} / z$ values of 130.10 and 146.09 , which correspond to OHP $\left(\mathrm{C}_{7} \mathrm{H}_{14} \mathrm{O}_{2}\right)$ and HPCE or KHP $\left(\mathrm{C}_{7} \mathrm{H}_{14} \mathrm{O}_{3}\right)$, respectively. The $2 \mathrm{MHX}$ model by Mohamed et al. [13] already includes alternative isomerization of $\mathrm{OOQOOH}$ radicals and the subsequent decomposition of $\mathrm{P}(\mathrm{OOH})_{2}$ 
radicals.

Figure $3 \mathrm{a}$ and $3 \mathrm{~b}$ present the PIE spectra and temperature-dependent profile of $\mathrm{C}_{7} \mathrm{H}_{14} \mathrm{O}_{2}$. The simulated temperature distribution of OHP agrees with the measurement at lower temperature, but decays faster after $600 \mathrm{~K}$. The reaction mechanisms suggests that $\mathrm{C}_{7} \mathrm{H}_{14} \mathrm{O}_{2}$ are likely to be olefinic hydroperoxides, but other isomers such as with alcohol and carbonyl groups may also exist. The rise in signal above $600 \mathrm{~K}$ might be due to the existence of other isomers and/or due to the scatter of the signal. The concerted elimination of $\mathrm{HO}_{2}$ from OOQOOH also forms OHPs. However, the JSR simulations show that these pathways are not dominant at the temperature range studied here. Table S2 shows the calculated IEs for the two most abundant OHPs from JSR simulations, i.e., $8.87 \mathrm{eV}$ (OHP-1 in Table S2, 2-methyl-2-hydroperoxy-hex-4-ene, mole fraction: $4.7 \times 10^{-5}$ ) and $8.41 \mathrm{eV}$ (OHP-2, 2-methyl-5-hydroperoxy-hex-2-ene, mole fraction: $3.2 \times 10^{-5}$ ), respectively. Figure 3a shows a measured IE onset of $8.5 \mathrm{eV}$, which is close to that of OHP-2, but $\sim 0.4 \mathrm{eV}$ lower than that of OHP-1. Although the mole fraction of OHP-1 is higher than that of OHP-2, its IE onset of $8.87 \mathrm{eV}$ is not evident in Fig. 3a.

The cyclization of $\mathrm{P}(\mathrm{OOH})_{2}$ radicals forms HPCE species, which have the same formula as KHP. The separation of HPCE from KHP is not feasible in the experiment. In this study, we tried to elucidate the HPCE structures only from the JSR simulations. The red dashed line in Fig 1c is the sum of the predicted HPCE mole fractions. In total the peak value is $\sim 17 \%$ that of KHP. The modeling results show that HPCEs are mainly composed of HPCE-1 (mole fraction: $1.9 \times 10^{-4}$ ), HPCE-2 (mole fraction: $1.0 \times 10^{-4}$ ), HPCE-3 (mole fraction: $6.6 \times 10^{-5}$ ), and HPCE-4 (mole fraction: $\left.2.0 \times 10^{-5}\right)$. These HPCEs in Scheme 2 are three-membered-ring cyclic ethers, having an $-\mathrm{OOH}$ attached to the secondary or tertiary carbon site and having a carbon atom separating the two functional groups. This analysis reveals that HPCEs are produced from the $\beta, \gamma-\mathrm{P}(\mathrm{OOH})_{2}$ radical, which requires that $\mathrm{ROO}$ isomerizes to $\mathrm{QOOH}$ via seven-membered TS rings, and $\mathrm{OOQOOH}$ isomerizes to $\mathrm{P}(\mathrm{OOH})_{2}$ via six-membered TS rings (the position of a carbon bonded to an $-\mathrm{OOH}$ group in a $\left(\mathrm{P}(\mathrm{OOH})_{2}\right.$ radical is designated by $\alpha, \beta, \gamma, \delta, \varepsilon$, respectively; $\alpha$ position is the carbon site 
with the radical).

\subsection{Third $\mathrm{O}_{2}$ addition to $\mathrm{P}(\mathrm{OOH})_{2}$}

Two high-molecular-weight species with $\mathrm{m} / z$, values $160.07\left(\mathrm{C}_{7} \mathrm{H}_{12} \mathrm{O}_{4}\right)$ and $178.08\left(\mathrm{C}_{7} \mathrm{H}_{14} \mathrm{O}_{5}\right)$ were detected in this work. The observation of $\mathrm{C}_{7} \mathrm{H}_{14} \mathrm{O}_{5}$ species indicates the presence of further $\mathrm{O}_{2}$ addition process, e.g., $\mathrm{O}_{2}+\mathrm{P}(\mathrm{OOH})_{2}$, during $2 \mathrm{MHX}$ low-temperature oxidation. The third $\mathrm{O}_{2}$ addition process was also observed during 2,5-dimethylhexane low-temperature oxidation by Wang et al. [4]. $\mathrm{C}_{7} \mathrm{H}_{14} \mathrm{O}_{5}$ species have two probable structures, i.e., KDHP and DHPCE (Scheme 1 and Table 1). For $\mathrm{OOP}(\mathrm{OOH})_{2}$ radicals, intramolecular $\mathrm{H}$-atom migrations from the $\mathrm{C}-\mathrm{H}$ alpha to the $-\mathrm{OOH}$ group and subsequent $\mathrm{C}-\mathrm{O} \beta$-scission produce $\mathrm{KDHP}+\mathrm{OH}$, while intramolecular $\mathrm{H}$-atom migrations from the $\mathrm{C}-\mathrm{H}$ not attached to the $-\mathrm{OOH}$ group form $\mathrm{T}(\mathrm{OOH})_{3}$ that further cyclize to $\mathrm{DHPCE}+\mathrm{OH}$.

Figure $4 \mathrm{a}$ and $4 \mathrm{~b}$ present the energy and temperature scans for $\mathrm{C}_{7} \mathrm{H}_{14} \mathrm{O}_{5}$ species. The predicted mole fractions of 43 probable KDHPs and 9 probable DHPCEs capture the temperature dependent distribution of $\mathrm{C}_{7} \mathrm{H}_{14} \mathrm{O}_{5}$ species. We calculated the IEs of $10 \mathrm{KDHPs}$ having mole fractions higher than 1 ppm (i.e., the detection limit of experiment), and their IEs in Table S3 range from 8.47 up to $9.45 \mathrm{eV}$.

Scheme 3 presents the reaction pathways for the seven most abundant KDHP isomers from simulations, i.e., KDHP-1 (mole fraction: $6.9 \times 10^{-5}$ ), KDHP-2 (mole fraction: $6.4 \times 10^{-5}$ ), KDHP-3 (mole fraction: $4.2 \times 10^{-5}$ ), KDHP-4 (mole fraction: $4.0 \times 10^{-5}$ ), KDHP-5 (mole fraction: $2.7 \times 10^{-5}$ ), KDHP-6 (mole fraction: $2.5 \times 10^{-5}$ ), and KDHP-7 (mole fraction: $1.3 \times 10^{-5}$ ). The formation of these KDHPs competes with the cyclization of $\mathrm{P}(\mathrm{OOH})_{2}$ to HPCE, such as HPCE-1, HPCE-2, and HPCE-3 in Scheme 2, and produce additional OH radicals [12]. The kinetics of KDHP formation based on the simulations are analyzed. First, the OOQOOH radicals produced from isomerization of ROO radicals via seven-membered (e.g., reaction a, f and g) and eight-membered TS rings (e.g., reaction $b$ and c) can easily undergo alternative isomerizations via six-membered TS rings; these reactions compete with the isomerization and formation of KHP via seven- and/or eight- membered 
TS rings. In addition, OOQOOH radicals from the primary fuel radical favor alternative isomerizations [4] (e.g., reactions a-e), which subsequently produce more KDHP. The presence of a tertiary carbon site also facilitates the third $\mathrm{O}_{2}$ addition process because its lower $\mathrm{C}-\mathrm{H}$ bond strength facilitates alternative isomerizations (e.g., reaction a, b, d, and f). Finally, OOQOOH radicals from the tertiary fuel radical cannot produce KHP, but can undergo alternative isomerization and third $\mathrm{O}_{2}$ addition, and finally form KDHP. Compared with the classical reaction scheme, reaction $\mathrm{g}$ shows that third $\mathrm{O}_{2}$ addition reactions divert the carbon flux to more reactive KDHP species.

The predicted mole fraction of DHPCEs in Fig. $4 \mathrm{~b}$ is $\sim 20 \%$ that of KDHPs because the further alternative isomerizations of $\mathrm{OOP}(\mathrm{OOH})_{2}$ radicals to $\mathrm{T}(\mathrm{OOH})_{3}$ radicals are less favorable than their isomerization and decomposition to KDHPs. Scheme 4 shows the reaction pathways for DHPCE-1, an important isomer for DHPCE.

Figure $4 \mathrm{c}$ and $4 \mathrm{~d}$ show the energy and temperature scans of $\mathrm{C}_{7} \mathrm{H}_{12} \mathrm{O}_{4}$ species. The potential structures of $\mathrm{C}_{7} \mathrm{H}_{12} \mathrm{O}_{4}$ species are DKHP and KHPCE (Scheme 1 and Table 1), which are produced from the $\mathrm{H}$-atom abstraction of $\mathrm{C}_{7} \mathrm{H}_{14} \mathrm{O}_{5}$ species, KDHP and DHPCE, respectively. The simulated mole fraction profiles of DKHP and KHPCE capture the temperature-dependent distribution of $\mathrm{C}_{7} \mathrm{H}_{12} \mathrm{O}_{4}$ species. The distribution of DKHP and KHPCE structures is related to the KDHP and DHPCE structures from which they are derived. This study calculated the IEs of 5 DKHPs having mole fractions higher than $1 \mathrm{ppm}$, which range from 9.11 up to $9.54 \mathrm{eV}$ (Table S4).

\subsection{MHX ignition simulations}

Recently, Wang and Sarathy [12] studied the effect of third $\mathrm{O}_{2}$ addition reactions on n-pentane and n-hexane low-temperature auto-ignition. The authors showed that the third $\mathrm{O}_{2}$ addition reactions only slightly promotes n-pentane ignition, but significantly advances n-hexane ignition. In this work we studied the effects of the third $\mathrm{O}_{2}$ addition on the ignition of a lean $2 \mathrm{MHX} /$ air mixture at 20 and 40 bar [13]. The ignition delay time was calculated in a closed homogenous batch reactor with constant volume profiles, using the CHEMKIN-Pro software [27].

Figure 5a shows that including the third $\mathrm{O}_{2}$ addition scheme reduces ignition delay time by a 
factor of two at $620 \mathrm{~K}$ (20 and $40 \mathrm{bar}$ ). The promotion is gradually diminished as temperature increases; for example, the ignition delay time is only $10 \%$ faster at $750 \mathrm{~K}$. As temperature increases, the third $\mathrm{O}_{2}$ addition reaction is inhibited by chemical equilibrium. In general, considering the third $\mathrm{O}_{2}$ addition and subsequent reactions improves the prediction of ignition delay time under the studied conditions. To elucidate the chemical effect of third $\mathrm{O}_{2}$ addition reactions, we compared the time-dependent distribution of key intermediates during ignition, such as $\mathrm{OH}, \mathrm{KHP}, \mathrm{HPCE}, \mathrm{C}_{7} \mathrm{H}_{14} \mathrm{O}_{5}$, and $\mathrm{C}_{7} \mathrm{H}_{12} \mathrm{O}_{4}$ species at $620 \mathrm{~K}$ and 20 bar. The results in Fig. 5 b-f show that the third $\mathrm{O}_{2}$ addition reactions cause $\mathrm{OH}, \mathrm{KHP}$, and $\mathrm{HPCE}$ to be produced at earlier time scales. The third $\mathrm{O}_{2}$ addition reactions slightly decrease the peak mole fraction of KHP and significantly decrease that of HPCE, thereby diverting the carbon flux to $\mathrm{C}_{7} \mathrm{H}_{14} \mathrm{O}_{5}$ (KDHP and DHPCE) and $\mathrm{C}_{7} \mathrm{H}_{12} \mathrm{O}_{4}$ (DKHP and KHPCE) species.

The initial accumulation of chain branching intermediates and their subsequent decomposition to release $\mathrm{OH}$ radicals drives the auto-ignition process. $\mathrm{C}_{7} \mathrm{H}_{14} \mathrm{O}_{3}$ species (KHP and HPCE) are the chain branching species in simulations without the third $\mathrm{O}_{2}$ addition reactions. When the third $\mathrm{O}_{2}$ addition reactions are considered, both $\mathrm{C}_{7} \mathrm{H}_{14} \mathrm{O}_{3}$ (KHP and HPCE) and $\mathrm{C}_{7} \mathrm{H}_{14} \mathrm{O}_{5}$ (KDHP and DHPCE) become the chain branching intermediates. Although the concentration of $\mathrm{C}_{7} \mathrm{H}_{14} \mathrm{O}_{5}$ species is only $30 \%$ of that of the $\mathrm{C}_{7} \mathrm{H}_{14} \mathrm{O}_{3}$ species, the barrierless third $\mathrm{O}_{2}$ addition reactions result in the formation of chain-branching precursors at lower temperatures (i.e., earlier reaction times) [12]. Thus, the formation and destruction of $\mathrm{C}_{7} \mathrm{H}_{14} \mathrm{O}_{5}$ species accelerates the accumulation of $\mathrm{OH}$ radicals and advances auto-ignition.

\section{Conclusions}

In this work, we studied the low-temperature oxidation chemistry of 2MHX through JSR oxidation experiment and kinetic modeling. Several key intermediates controlling the auto-ignition process, especially OHP, $\mathrm{C}_{7} \mathrm{H}_{14} \mathrm{O}_{3}, \mathrm{C}_{7} \mathrm{H}_{14} \mathrm{O}_{5}$, and $\mathrm{C}_{7} \mathrm{H}_{12} \mathrm{O}_{4}$ species, were observed. The mechanisms leading to their formation were elucidated with chemical kinetic simulations. The simulations reveal that the primary and tertiary carbon sites of $2 \mathrm{MHX}$ facilitate the extended low-temperature auto-oxidation 
scheme. The extended reaction mechanism, promotes low-temperature auto-ignition of $2 \mathrm{MHX}$ due to the barrierless third $\mathrm{O}_{2}$ addition reactions, accompanied by the formation and destruction of $\mathrm{C}_{7} \mathrm{H}_{14} \mathrm{O}_{5}$ species (KDHP and DHPCE) to form additional $\mathrm{OH}$ radicals.

\section{Supplemental Material}

The structures and calculated ionization energies in Table $\mathrm{S} 1-\mathrm{S} 4$ for $\mathrm{C}_{7} \mathrm{H}_{14} \mathrm{O}_{3}, \mathrm{C}_{7} \mathrm{H}_{14} \mathrm{O}_{2}, \mathrm{C}_{7} \mathrm{H}_{14} \mathrm{O}_{5}$, and $\mathrm{C}_{7} \mathrm{H}_{12} \mathrm{O}_{4}$ species; $2 \mathrm{MHX}$ kinetic model including the third $\mathrm{O}_{2}$ addition and subsequent reactions.

\section{Acknowledgements}

This work was supported by: King Abdullah University of Science and Technology (KAUST) and Saudi Aramco under the FUELCOM program; National Key Scientific Instruments and Equipment Development Program of China 2012YQ22011305; Department of Energy Gas Phase Chemical Physics Program at Lawrence Berkeley National Laboratory DEAC02-05CH11231; German DFG project Ko1363/31-1; European Research Council under FP7/2007-2013/ERC grant 291049-2G-CSafe; Sandia Corporation, a Lockheed Martin Company, and under National Nuclear Security Administration contract DE-AC04-94-AL85000. The Advanced Light Source is supported by the Director, Office of Science, Office of Basic Energy Sciences, of the U.S. Department of Energy under Contract No. DEAC02-05CH11231.

\section{References}

[1] S.M. Sarathy, G. Kukkadapu, M. Mehl, W. Wang, T. Javed, S. Park, M.A. Oehlschlaeger, A. Farooq, W.J. Pitz, C.-J. Sung, Proc. Combust. Inst. 35 (2015) 249-257.

[2] A. Ahmed, G. Goteng, V.S.B. Shankar, K. Al-Qurashi, W.L. Roberts, S.M. Sarathy, Fuel 143 (2015) 290-300.

[3] S.M. Sarathy, G. Kukkadapu, M. Mehl, T. Javed, A. Ahmed, N. Naser, A. Tekawade, G. Kosiba, M. AlAbbad, E. Singh, S. Park, M.A. Rashidi, S.H. Chung, W.L. Roberts, M.A. Oehlschlaeger, C.-J. Sung, A. Farooq, Combust. Flame 169 (2016) 171-193.

[4] Z.D. Wang, L. Zhang, K. Moshammer, D.M. Popolan-Vaida, V.S. Bhavani Shankar, A. Lucassen, C. Hemken, C.A. Taatjes, S.R. Leone, K. Kohse-Höinghaus, N. Hansen, P. Dagaut, S.M. Sarathy, Combust. Flame 164 (2016) 386-396.

[5] C.K. Westbrook, W.J. Pitz, H.C. Curran, J. Boercker, E. Kunrath, Int. J. Chem. Kinet. 33 (2001) 868-877. 
[6] E.J. Silke, H.J. Curran, J.M. Simmie, Proc. Combust. Inst. 30 (2005) 2639-2647.

[7] S.M. Sarathy, C.K. Westbrook, M. Mehl, W.J. Pitz, C. Togbé, P. Dagaut, H. Wang, M.A. Oehlschlaeger, U. Niemann, K. Seshadri, P.S. Veloo, C. Ji, F.N. Egolfopoulos, T. Lu, Combust. Flame 158 (2011) 2338-2357.

[8] F. Battin-Leclerc, Prog. Energy Combust. Sci. 34 (2008) 440-498.

[9] E. Ranzi, C. Cavallotti, A. Cuoci, A. Frassoldati, M. Pelucchi, T. Faravelli, Combust. Flame 162 (2015) 1679-1691.

[10] J. Bugler, K.P. Somers, E.J. Silke, H.J. Curran, J. Phys. Chem. A 119 (2015) 7510-7527.

[11] K. Zhang, C. Banyon, C. Togbé, P. Dagaut, J. Bugler, H.J. Curran, Combust. Flame 162 (2015) 4194-4207.

[12] Z.D. Wang, S.M. Sarathy, Combust. Flame 165 (2016) 364-372.

[13] S.Y. Mohamed, L. Cai, F. Khaled, C. Banyon, Z. Wang, M.J. Al Rashidi, H. Pitsch, H.J. Curran, A. Farooq, S.M. Sarathy, J. Phys. Chem. A 120 (2016) 2201-2217.

[14] F. Battin-Leclerc, O. Herbinet, P.-A. Glaude, R. Fournet, Z. Zhou, L. Deng, H. Guo, M. Xie, F. Qi, Angew. Chem. Int. Edit. 49 (2010) 3169-3172.

[15] F. Battin-Leclerc, O. Herbinet, P.-A. Glaude, R. Fournet, Z. Zhou, L. Deng, H. Guo, M. Xie, F. Qi, Proc. Combust. Inst. 33 (2011) 325-331.

[16] Z.D. Wang, O. Herbinet, Z.J. Cheng, B. Husson, R. Fournet, F. Qi, F. Battin-Leclerc, J. Phys. Chem. A 118 (2014) 5573-5594.

[17] K. Moshammer, A.W. Jasper, D.M. Popolan-Vaida, A. Lucassen, P. Diévart, H. Selim, A.J. Eskola, C.A. Taatjes, S.R. Leone, S.M. Sarathy, Y. Ju, P. Dagaut, K. Kohse-Höinghaus, N. Hansen, J. Phys. Chem. A 119 (2015) 7361-7374.

[18] J.A. Montgomery, M.J. Frisch, J.W. Ochterski, G.A. Petersson, J. Chem. Phys. 110 (1999) 2822-2827.

[19] R.B. M. J. Frisch et al. Gaussian 09, Gaussian, Inc., Wallingford CT, (2009).

[20] S. Sharma, S. Raman, W.H. Green, J. Phys. Chem. A 114 (2010) 5689-5701.

[21] A. Miyoshi, J. Phys. Chem. A 115 (2011) 3301-3325.

[22] S.M. Burke, J.M. Simmie, H.J. Curran, J. Phys. Chem. Ref. Data 44 (2015) 013101.

[23] S.M. Villano, L.K. Huynh, H.-H. Carstensen, A.M. Dean, J. Phys. Chem. A 115 (2011) 13425-13442.

[24] S.M. Villano, L.K. Huynh, H.-H. Carstensen, A.M. Dean, J. Phys. Chem. A 116 (2012) 5068-5089.

[25] S.M. Villano, H.-H. Carstensen, A.M. Dean, J. Phys. Chem. A 117 (2013) 6458-6473.

[26] E.R. Ritter, J.W. Bozzelli, Int. J. Chem. Kinet. 23 (1991) 767-778.

[27] CHEMKIN-PRO 15112, Reaction Design: San Diego, (2012). 


\section{Figure Captions}

(Color figures in electronic version only)

Scheme 1. Extended reaction scheme of OOQOOH radical $[4,12]$. The pathways included in $2 \mathrm{MHX}$ kinetic model [13] are annotated with dashed arrows; the extended third $\mathrm{O}_{2}$ addition pathways studied in this work are annotated with blue solid lines.

Figure 1. (a) Mass spectrum from $2 \mathrm{MHX}$ oxidation at $560 \mathrm{~K}$ and photon energy of $10.5 \mathrm{eV}$. The peaks labeled with a molecular formula are discussed in the text; (b) Temperature dependent profiles for the measured (symbols) and simulated (lines) mole fraction of 2MHX; and (c) the signal of $\mathrm{C}_{7} \mathrm{H}_{14} \mathrm{O}_{3}$ (symbols, right axis) and simulated mole fraction of KHP and HPCE (lines, left axis).

Figure 2. Energy scan of $\mathrm{C}_{7} \mathrm{H}_{14} \mathrm{O}_{3}$ in $2 \mathrm{MHX}$ low-temperature oxidation at $560 \mathrm{~K}$. The signals annotated with red and circle are multiplied by a factor of 10 to denote the onset.

Figure 3. (a) Energy scan of $\mathrm{C}_{7} \mathrm{H}_{14} \mathrm{O}_{2}$ from $2 \mathrm{MHX}$ low-temperature oxidation at $560 \mathrm{~K}$. (b) Temperature dependent profiles for the measured signal (symbol) and simulated mole fraction (line, right axis) of $\mathrm{C}_{7} \mathrm{H}_{14} \mathrm{O}_{2}$.

Scheme 2. The structures of the most abundant HPCEs.

Figure 4. Energy (upper) and temperature (lower) scans of (a, b) $\mathrm{C}_{7} \mathrm{H}_{14} \mathrm{O}_{5}$ and (c, d) $\mathrm{C}_{7} \mathrm{H}_{12} \mathrm{O}_{4}$ in 2MHX low-temperature oxidation at $560 \mathrm{~K}$ and $9.5 \mathrm{eV}$, respectively. The symbols are measured signal and lines (right axis) are the simulated mole fractions in (b) and (d).

Scheme 3. Selected reactions for $\mathrm{OOQOOH}$ alternative isomerization, third $\mathrm{O}_{2}$ addition, and decomposition to KDHP.

Scheme 4. Reaction pathways for DHPCE-1 formation.

Figure 5. (a) Ignition delay times for $2 \mathrm{MHX}$ /air mixtures at $\varphi=0.5,20$ and 40 bar. The open circle, red dash line, and red solid line are ignition delay time by experiment, simulation without third $\mathrm{O}_{2}$ addition reactions, and simulation with third $\mathrm{O}_{2}$ addition reactions at 20 bar, respectively; The solid triangle, black dash line, and black solid line are ignition delay time by experiment, simulation without third $\mathrm{O}_{2}$ addition reactions, and simulation with third $\mathrm{O}_{2}$ addition reactions at 40 bar, respectively. (b)-(f) Time-dependent distribution of $\mathrm{OH}$, KHP, $\mathrm{HPCE}, \mathrm{C}_{7} \mathrm{H}_{14} \mathrm{O}_{5}$, and $\mathrm{C}_{7} \mathrm{H}_{12} \mathrm{O}_{4}$ at 620 $\mathrm{K}$ and 20 bar. Open symbols and blue lines: simulation without third $\mathrm{O}_{2}$ addition reactions [13]; lines: simulation with third $\mathrm{O}_{2}$ addition reactions. 


\section{Table}

Table 1. Rate rules utilized for the third $\mathrm{O}_{2}$ addition reaction mechanism.

\begin{tabular}{|c|c|c|c|c|}
\hline Reactions & Reaction type & Analogous Reaction & Refs. & Example \\
\hline $\mathrm{O}_{2}+\mathrm{P}(\mathrm{OOH})_{2}=\mathrm{OOP}(\mathrm{OOH})_{2}$ & $\mathrm{O}_{2}$ addition & $\mathrm{O}_{2}+\mathrm{QOOH}=\mathrm{OOQOOH}$ & [21] & \\
\hline $\mathrm{OOP}(\mathrm{OOH})_{2}=\mathrm{ODHP}+\mathrm{HO}_{2}$ & $\begin{array}{l}\text { Concerted } \\
\text { elimination }\end{array}$ & $\mathrm{OOQOOH}=\mathrm{OHP}+\mathrm{HO}_{2}$ & [23] & \\
\hline $\mathrm{OOP}(\mathrm{OOH})_{2}=\mathrm{KDHP}+\mathrm{OH}$ & $\begin{array}{l}\text { H-migration, } \\
\beta \text {-scission }\end{array}$ & $\mathrm{OOQOOH}=\mathrm{KHP}+\mathrm{OH}$ & [20] & \\
\hline $\mathrm{OOP}(\mathrm{OOH})_{2}=\mathrm{T}(\mathrm{OOH})_{3}$ & H-migration & $\mathrm{OOQOOH}=\mathrm{P}(\mathrm{OOH})_{2}$ & [23] & \\
\hline $\mathrm{T}(\mathrm{OOH})_{3}=\mathrm{DHPCE}+\mathrm{OH}$ & Cyclization & $\mathrm{P}(\mathrm{OOH})_{2}=\mathrm{HPCE}+\mathrm{OH}$ & [24] & \\
\hline $\mathrm{T}(\mathrm{OOH})_{3}=\mathrm{ODHP}+\mathrm{HO}_{2}$ & $\mathrm{C}-\mathrm{O} \beta$-scission & $\mathrm{P}(\mathrm{OOH})_{2}=\mathrm{OHP}+\mathrm{HO}_{2}$ & [25] & \\
\hline $\begin{array}{l}\mathrm{KDHP}+\mathrm{OH}=\mathrm{H}_{2} \mathrm{O}+\mathrm{OH}+ \\
\text { DKHP }\end{array}$ & $\begin{array}{l}\text { H-abstraction, } \\
\beta \text {-scission }\end{array}$ & $\mathrm{KHP}=\mathrm{H}_{2} \mathrm{O}+\mathrm{OH}+\mathrm{DKET}$ & [9] & \\
\hline $\begin{array}{l}\text { DHPCE+OH }= \\
\mathrm{H}_{2} \mathrm{O}+\mathrm{OH}+\mathrm{KHPCE}\end{array}$ & $\begin{array}{l}\text { H-abstraction, } \\
\beta \text {-scission }\end{array}$ & $\mathrm{KHP}=\mathrm{H}_{2} \mathrm{O}+\mathrm{OH}+\mathrm{DKET}$ & [9] & \\
\hline $\begin{array}{l}\text { ODHP, KDHP, DHPCE, } \\
\text { DKHP, and KHPCE } \\
\text { decomposition }\end{array}$ & $\begin{array}{l}-\mathrm{OOH} \\
\text { dissociation }\end{array}$ & $\mathrm{KHP}=$ products & [7] & Scheme 1 \\
\hline
\end{tabular}




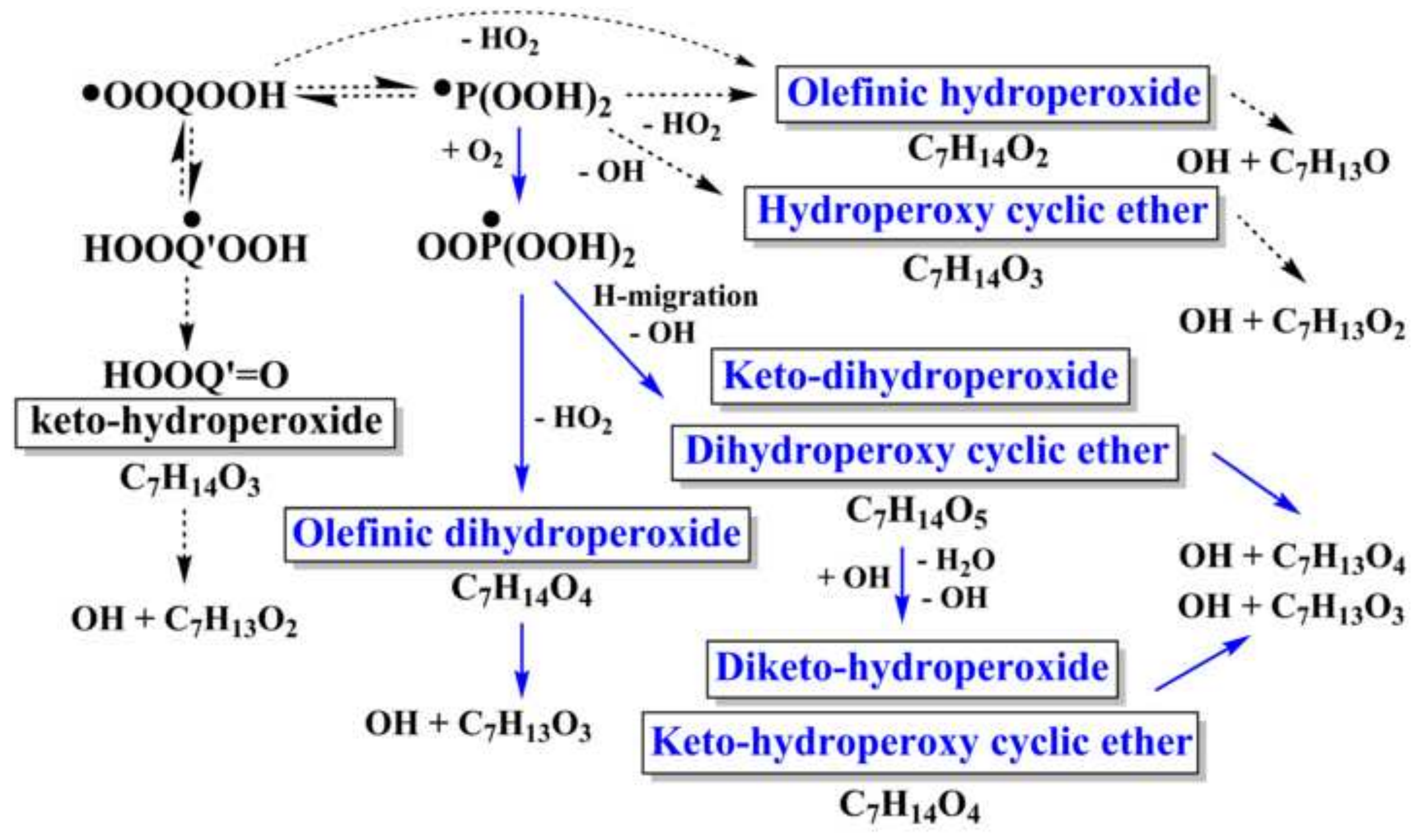



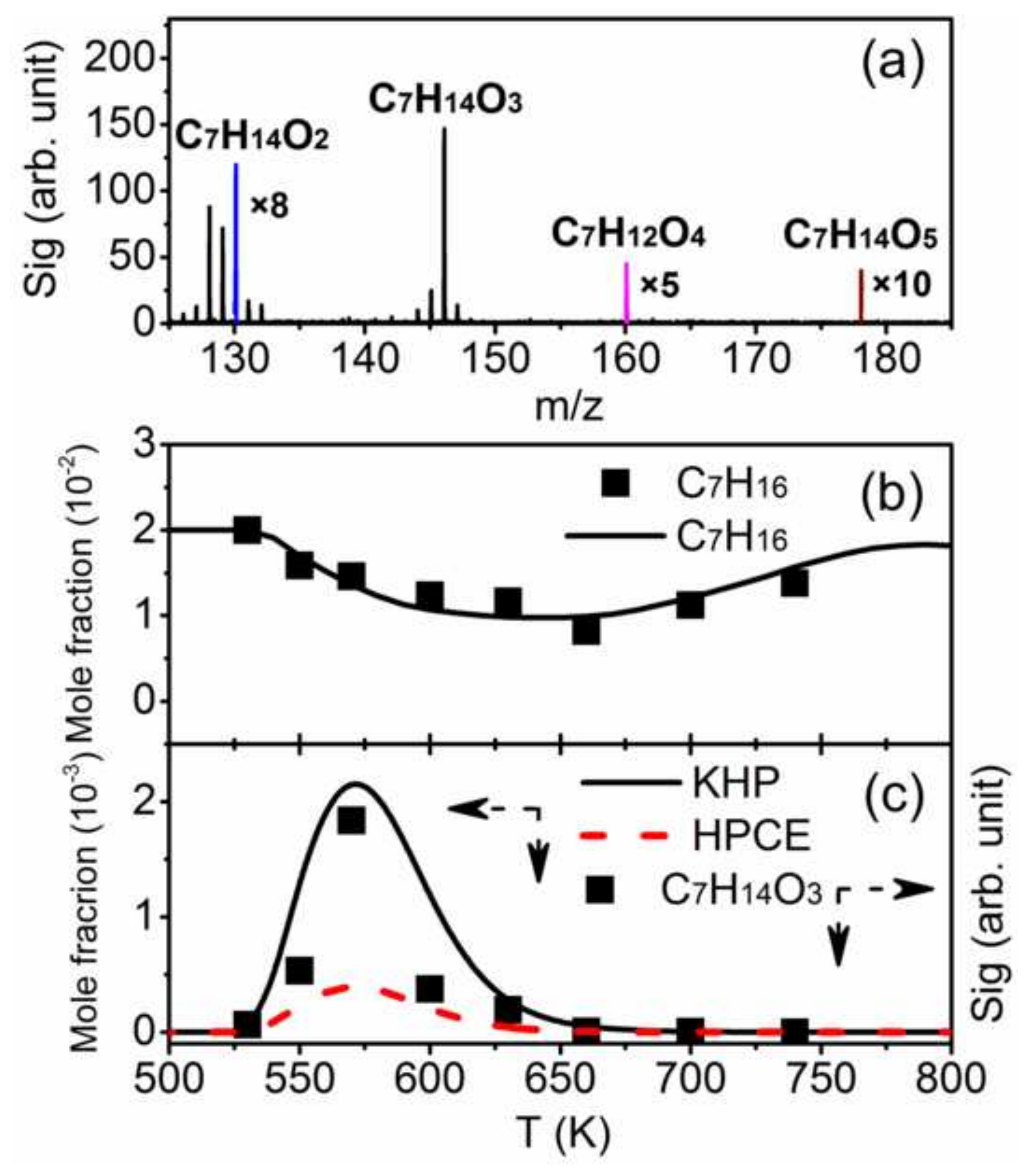


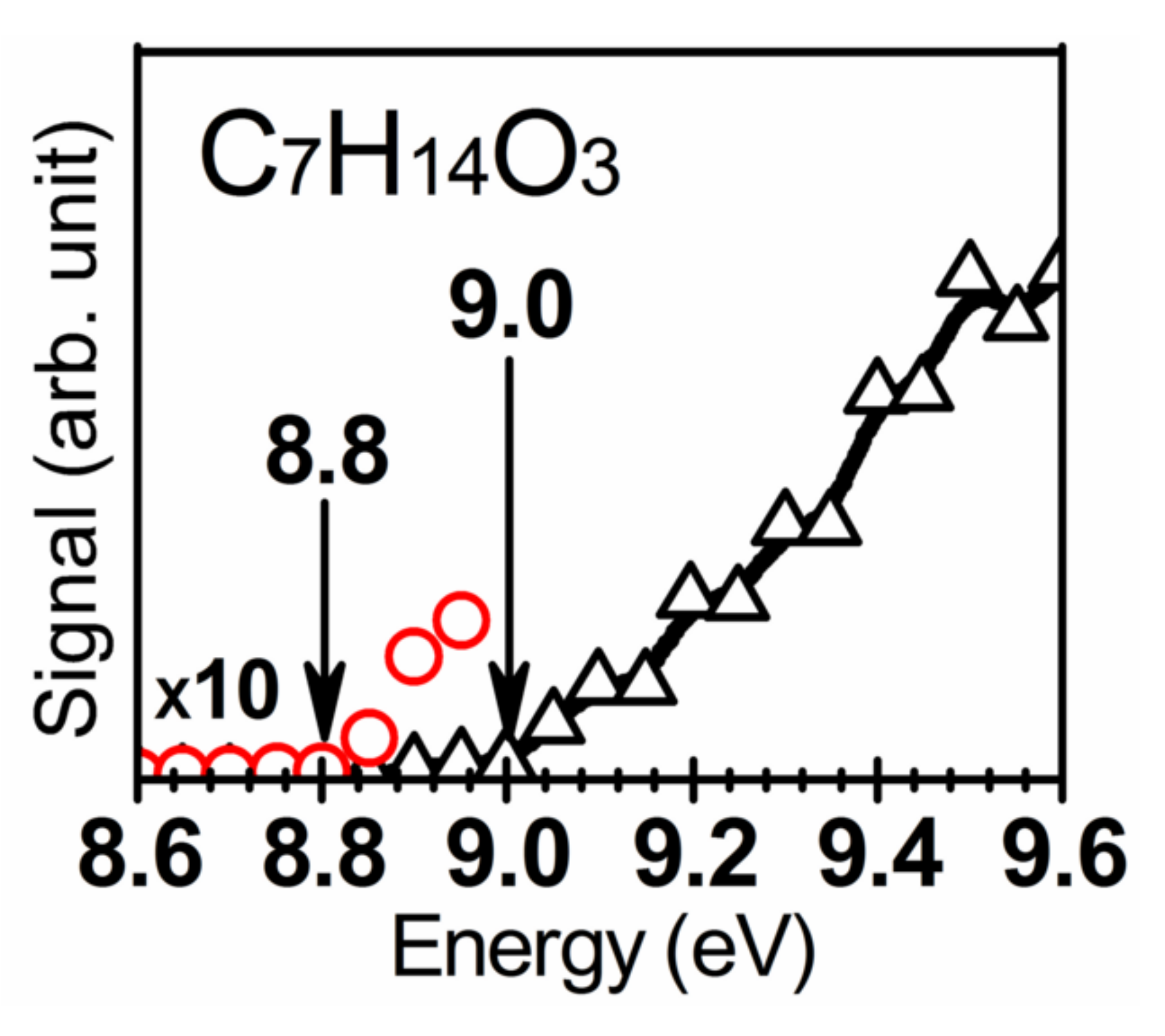

Figure 2

.

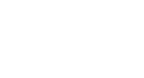

.

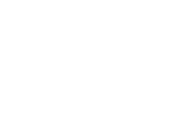




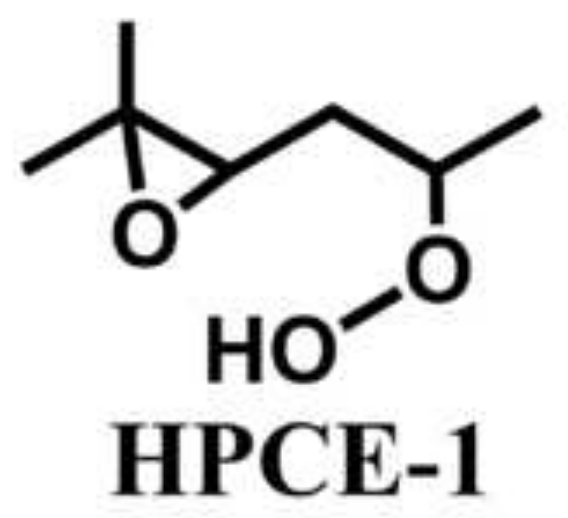

HPCE-1

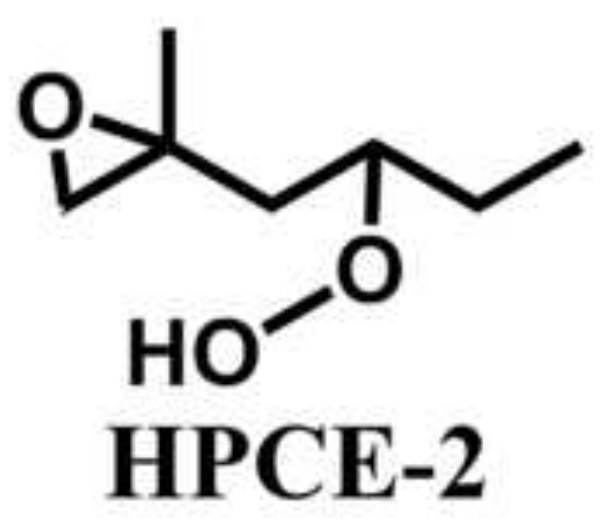

HPCE-2

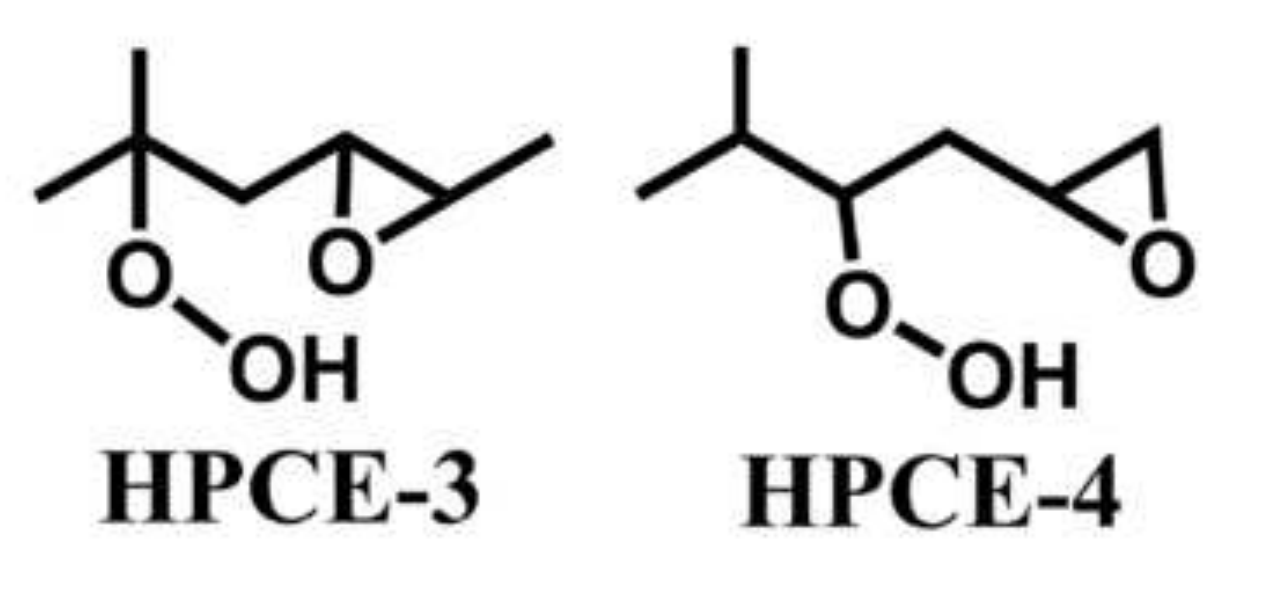

HPCE-3
HPCE-4

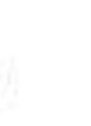

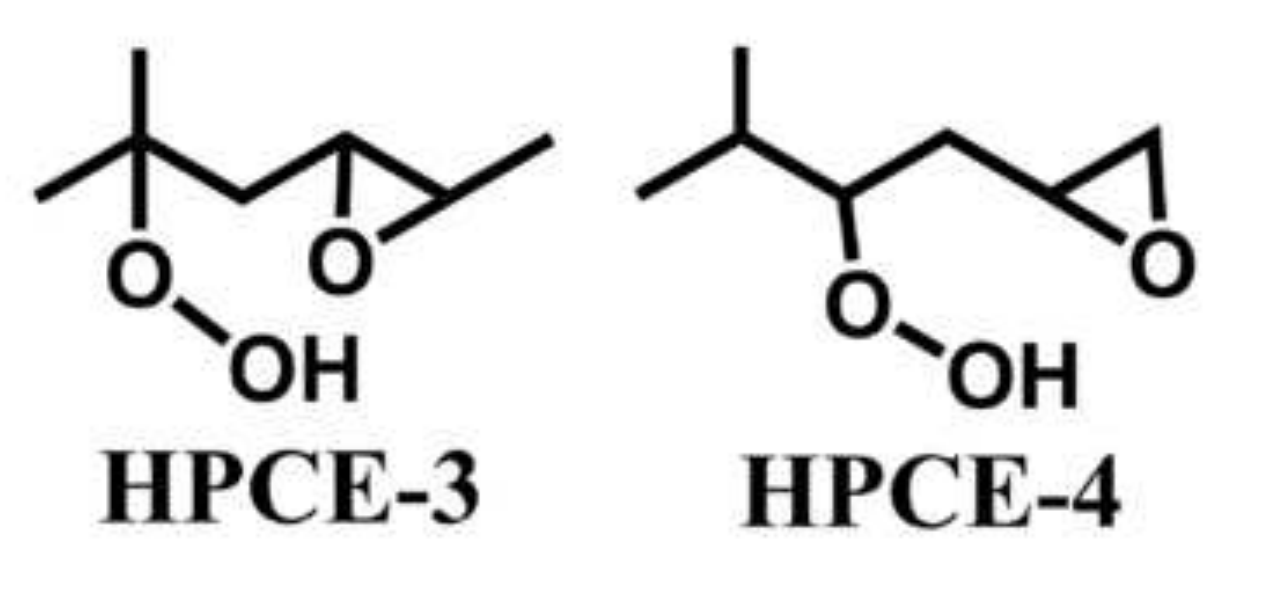

.




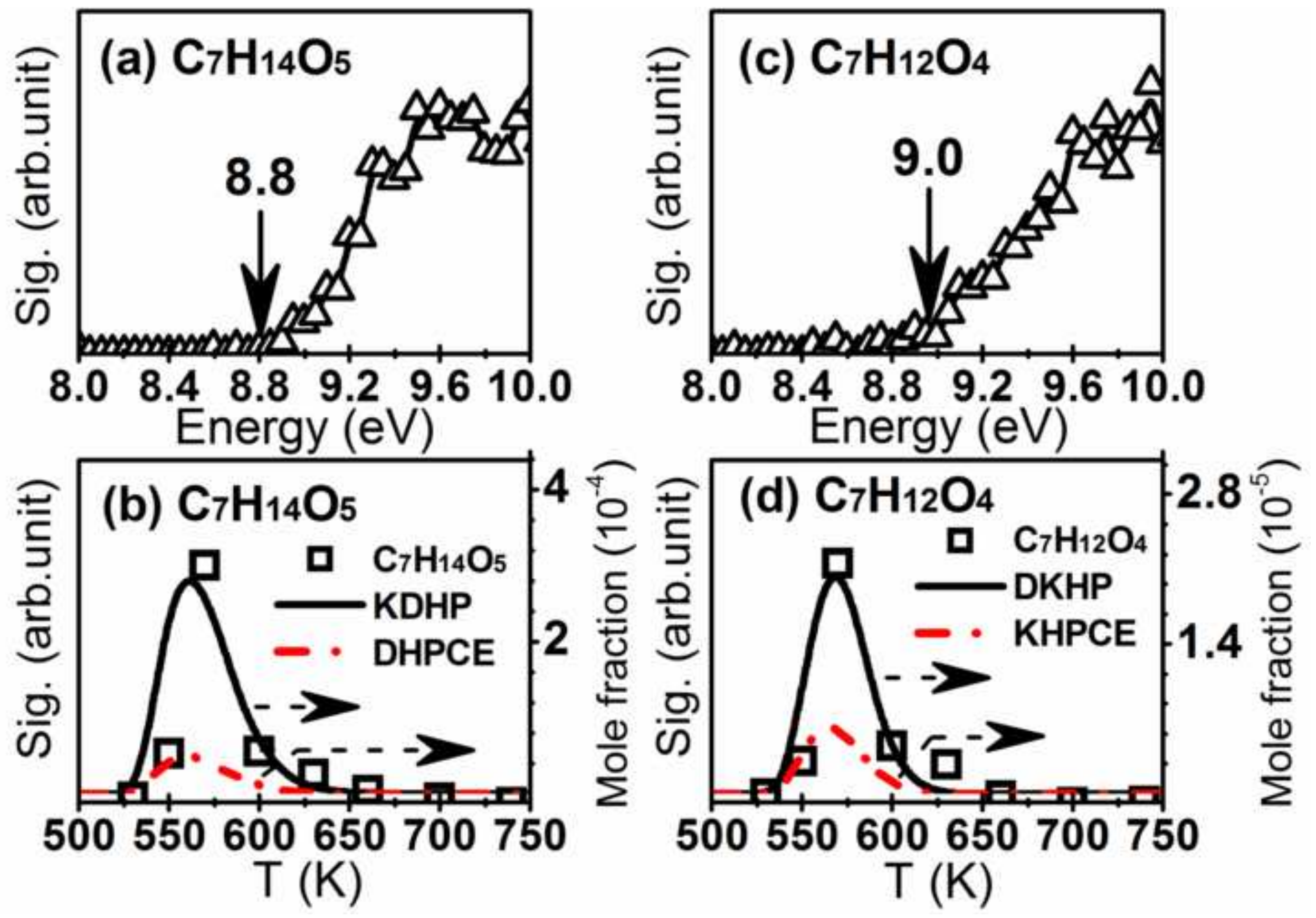



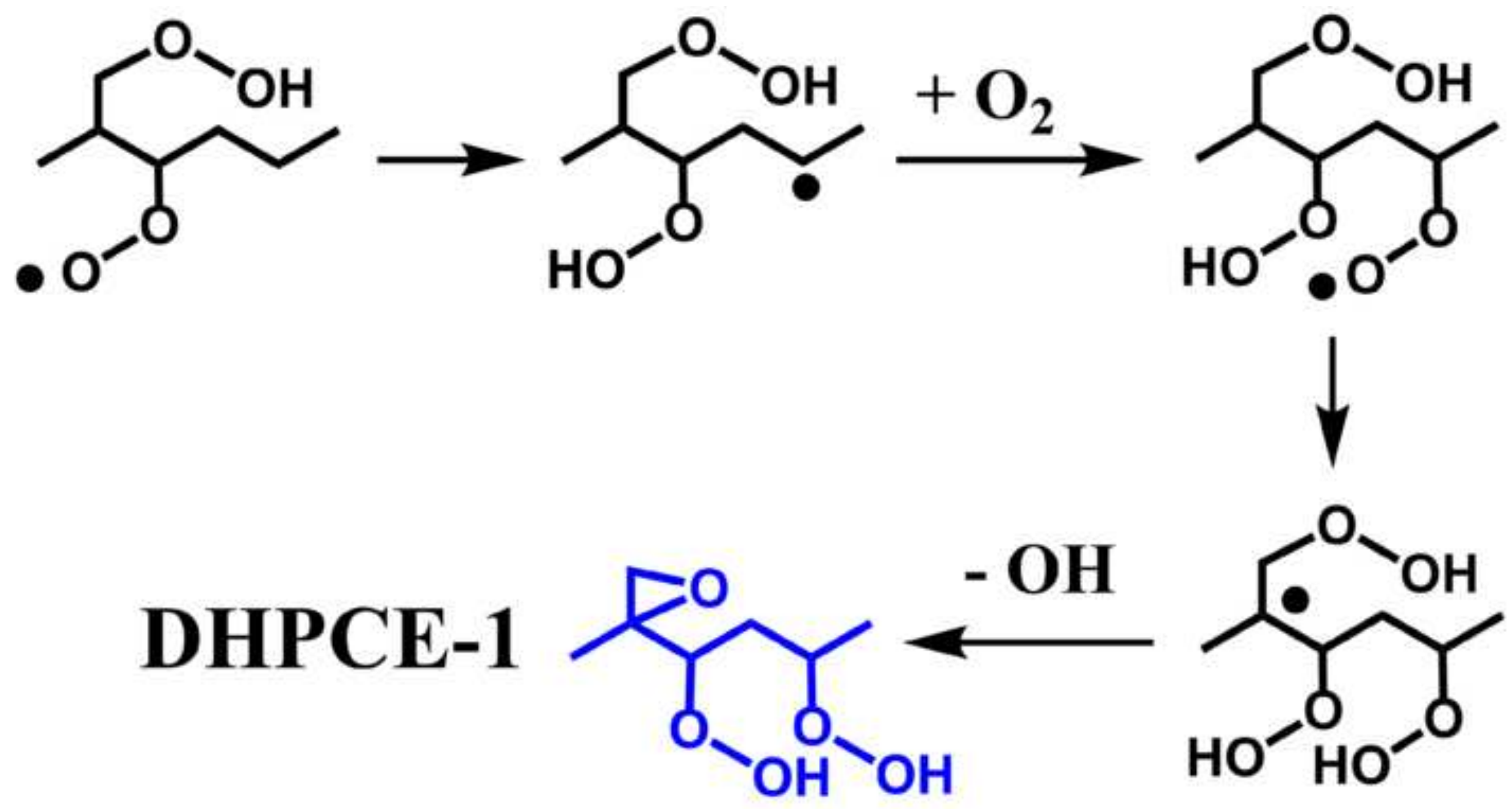

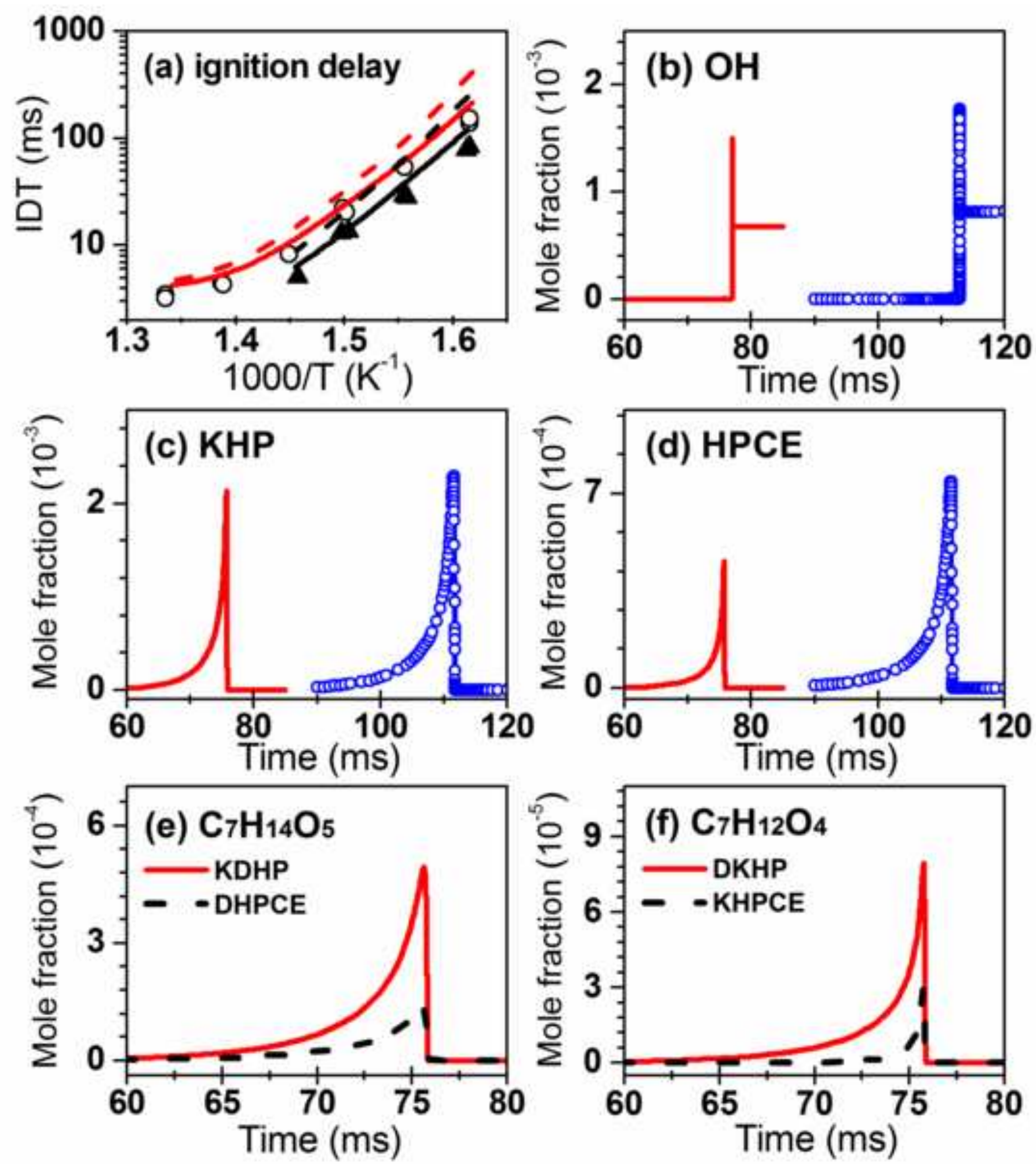